\title{
从毕业开始,重拾生活主权一一浅谈在疫情期间因多重人际压力 而想休学的学生成长辅导
}

\author{
江洁 \\ 长沙理工大学 \\ DOI:10.32629/er.v3i5.2770
}

[摘 要] 在多重人际压力叠加的情况下,很多高校毕业生的心理健康状况不容乐观,表现为情绪上心理状态失衡,或焦虑不安或悲观消沉; 认知 上出现偏差,或前景迷茫或盲目从众。因此, 我们要在尊重大学生心理发展特征的基础上,结合疫情下所呈现的问题探索毕业生成长辅导的有效 途径,促进大学生心理健康状况的改善。

[关键词] 人际压力; 高校毕业生; 心理辅导

\section{1 辅导案例分析}

1. 1 基本情况

小李, 研三学生, 家里独子, 家庭经济状况尚可, 在校期间表现良好, 导 师对该生评价较高。疫情期间, 班长反馈该生经常不按时进行每日健康汇 报, 研究生辅导员排查后发现该生一周内出现5次不按时汇报现象, 马上线 上约谈该生。该生表示因最近謷夜查文献而错过汇报时间, 同时咨询研究 生辅导员是否可以线上办理休学事宜, 由于远程交流不可控因素较多, 研 究生辅导员为稳定该生情绪, 与该生协商先去科研办咨询再准确答复。

1. 2 辅导原因

该生毕业在即, 目前已签约一家私企, 导师也表示按照进展毕业论文 不成问题, 但却跟研究生辅导员提出休学, 研究生辅导员把这一异常情况 反馈至心理辅导员, 及时做好转介工作。

在电话交流中, 小李表示自己近 1 个月整体状态很不好, 每天前半夜查 文献, 后半夜辗转难眠, 白天一睡睡到 11 点多, 整天没什么精神, 感觉每天 被各种现实问题压得喘不过气来, 有时觉得自己很没用, 否认存在极端想 法和行为。考虑到该生长时间情绪低落和远程辅导局限性, 心理辅导员建 议该生去附近医院心理咨询科就诊或预约心理援助热线, 但该生都给予拒 绝, 理由一是疫情期间往返医院新冠肺炎感染风险较高, 二是觉得学院心 理辅导员更了解自己的实际情况, 辅导效果会比心理援助热线要好。在尊 重学生个人意愿以及考虑当下暂无生命安全风险, 同时也不属于精神疾病 发作状态, 心理辅导员对该生进行线上成长辅导, 每次将辅导内容及时反 馈至学校心理中心, 心理中心给予专业指导和建议。

\section{2 辅导过程}

单从该生想休学的行为来看, 辅导定位应是学业发展问题, 但通过全 面梳理该生压力源, 发现该生与周边重要关系人都存在不同程度的意见分 歧的情况, 造成超负荷压力, 这才是引发异常情绪波动和深深无助感的主 要原因。辅导老师一方面注重他的内在需求, 聚焦于人际交往的技巧, 探索 积极心理品质的培育; 另一方面, 逐一与周边重要关系人线上沟通, 了解他 们心目中小李有哪些积极品质, 并强化和搭建多方的沟通桥梁。

2.1第一次线上辅导: 宜拉近距离, 疫路有 “苦” 心人

通过建立适宜的辅导关系, 辅导老师耐心倾听小李诉苦, 小李表达自 己对于周边人 “苦口婆心” 的不满, 采用具体化技术引导小李从抽象概括 过渡到具体分析困扰自己的原因, 归纳出压力源主要来源于三个方面: 迎 合家人的过高期望、渴望导师的学术认可、回避女友的未来憧憬。

2. 2 第二次线上辅导: 依优势资源, 疫路有 “用” 心人

理清小李与周边的人际交往关联, 分析产生冲突的具体情境, 澄清事
实并重新归纳小李的自我表述分别为不想喜负家人的期昐、导师的希冀、 女友的憧憬, 让小李体谅周边人的“用心良苦”, 学会适当依靠大家的力量。 所以第二次辅导重点在于识别小李内在的积极品质, 辅助他利用外在环境 的优势资源, 避免单一视角情绪化看待问题。

\subsection{1 善用亲情和缓就业争执}

辅导老师从小李从小就愿意采纳和相信家人的选择, 对待家人是信任 和顺从态度的成长历程, 引导小李理性看待亲子关系, 感受父母对他的爱 和关心从来没变, 依然可以像从前从一样信任、信赖他们。

2.2.2妙用恩情延缓学术摩擦

辅导老师从小李总能按时完成分配任务并持有自己学术观点的求学 之路, 疏导小李客观看待师生关系, 体会导师对他一直寄予厚望, 学术要求 严谨是对他学业的负责, 依旧可以多多跟导师讨论学术问题, 听取老师中 肯建议。

\subsection{3巧用爱情舒缓情感冲突}

辅导老师从小李对女友嘘寒问暖和在亲密关系中处于付出方的情感 经历, 指导小李全面看待亲密关系, 相信女友对他的喜爱和依赖不会降温, 依然可以好好培养感情和经营他们的爱情。

2.3 第三次线上辅导: 仪真实自我, 疫路有 “真” 心人

通过深入的分析, 鼓励小李理性看待问题, 悦纳真实的自己, 看清真实 需求和想法, 让他认识自己有退学的想法并不是真的不想学习, 而是逃避 与周边人的人际交流。辅导老师与小李的父母、导师、女友的逐一沟通, 寻找并肯定小李的积极品质, 让对方感觉到自己的 “真情实意”, 促进他们 之间的积极互动。

\section{3. 1 真情感召, 换成长的蜕变}

父母认为自己的孩子是孝顺和聪慧, 他们自信告诉辅导老师, 小李肯 定会找到理想的工作, 通过辅导老师的有效反馈, 小李更加坚定就业方向 的选择。

2. 3. 2 真诚引导, 点亮毕业之灯

导师认为小李的优点是勤奋和耐心, 他笃信小李有能力顺利完全毕业 设计, 通过辅导老师的有效反馈, 小李对顺利按期毕业充满信心。

2. 3. 3 真爱温暖, 一路相携相伴

小李作为男友最大魅力是负责任和踏实, 女友肯定回应辅导老师, 她 相信未来的日子会是美好的, 通过辅导老师的有效反馈, 小李看待两性关 系更全面。

2. 4第四次线上辅导: 忆处境鼓励, 疫路有 “决”心人 通过回忆和对比以往交流方式, 小李尝试用新的视角去看待与周边人 
的关系, 用新的言语方式去表达内心的想法, 用新的处事方法去应对人际 冲突, 打消自己的“犹豫不决”。同时, 辅导老师布置家庭作业给小李, 用“我 是怎样和应该怎样”记录和重新梳理沟通内容, 从而重建良好的交流方式, 重新审视与他人的关系, 缓解并化解因沟通不畅产生的矛盾与误会。

2.4.1 择业问题决不含糊

在与家人的 “沟通” 中, 小李记录着 “我身上承载着太多父母的爱, 他们建议我考事业单位, 希望我以后老有所依, 不希望忙碌一辈子, 我应 该多多考虑他们的感受, 而不是一味回避他们, 找个时间我要跟他们好 好谈谈。”

\section{4.2 毕业问题决不拖拉}

在与导师的 “沟通” 中, 小李记录着 “导师是一个做事很严谨仔细的 人, 他相信我有能力完成毕业设计, 才会放心让我去接力完成系列实验, 而 且在毕业设计的过程中, 导师一直都是亲自指导, 他希望我能在科研方面 有所新突破, 我应该迎难而上。”

2.4.3 情感问题决不动摇

在与女友的 “沟通” 中, 小李记录着 “婚姻对一个女人来说是一辈子 的事情, 我现在什么都没有, 女友坚定地跟我相处下去, 我也应该好好奋斗, 不能辜负女友对我的期待与肯定。”

2. 5第五次线上辅导: 议积极关系, 疫路有 “初” 心人

鼓励小李将新的认知和行为模式应用到生活中, 与周边人商议建议积 极的人际关系, 明确自身人际交往目标, 聚焦自身优势发现闪光点, 重拾生 活管理的主权, 找回自己的 “初心”, 而不是退缩和逃避, 肩负起自己家庭、 学业、爱情的重任。通过理性看待他人的意见, 及时疏通 “堵点” 和 “断 点”, 学会换位思考, 让小李的人际交往模式从被动变为主动。

2.5.1果敢抉择, 初衷择业稳解决

小李跟父母耐心讨论自己的人生规划, 同时把自己真实想法分享给父 母, 让父母相信自己能够承担责任, 敢于经受社会的考验, 表示日后不会后 悔当下的选择。

\section{5. 2清晰判断, 初显成果思进取}

小李重新看待毕业设计的意义, 将它看成一个持续的过程, 这个过程 充满激励体验和智慧增长。同时把文献搜索的工作拆分成不同的挑战, 拆 分成自己想要发现每一个细节的部分, 这更易于自己投入学业中。

2.5.3勇于担当, 初恋情感携共进

小李表示近期多用心跟女友详谈一起奋斗的近远期目标, 并与女友协 商先解决眼前的工作问题, 会跟女友提及父母的兴趣喜好, 找准机会把女 友介绍给父母认识。

\section{3 辅导效果}

隔屏不隔心, 隔键不隔情, 隔离不隔爱。线上成长辅导不仅让小李从学 业中获得新的见解，也使他从交流对象身上获得新的洞见。小李体会到亲 情的无私、拥有了爱情的坚守、感受到导师的关爱, 发掘到周边人的可贵 品质。

女友在父母的建议下备考当地市区的事业单位, 现在已与父母相处 融洽。小李体验学业的热情, 发挥主动能动性, 自主开始他的毕业设计, 他总会有新的想法并向导师寻求指导, 而导师也给予了肯定和鼓励, 他 围绕研究领域展开文献阅读, 并做相应的延伸思考, 将工作拆成可以管
理的目标, 定期完成指定任务。答辩完后, 小李计划提前去单位报道, 及早 融入新环境。

\section{4 辅导反思}

4. 1 思政因疫而变, 辅导安心安适安全

本案例是辅导对象涉及范围广、辅导可控性难掌握、辅导难度较高的 一次线上成长辅导, 针对该生自身的积极品质和人际能力发展空间较大的 特点, 辅导老师全程做到 “用心倾听” 和 “积极肯定”, 聚焦该生自身的优 势品质和周边资源优势。疫情期间, 网络碎片化信息、封闭的外部环境、 单一的人际交流等易引发学生亚健康的心理状态, 辅导员作为高校疫情防 控的主力军, 一方面, 准确把握與论导向, 精准实时网络监控, 积极正面教 育引导, 牢牢抓住思政话语权, 樂住生命安全底线, 确保学生健康成长; 另 一方面, 实时分析研判, 及时准确报送, 持续跟踪反馈, 加强辅导员在网络 环境下大学生思想政治教育与日常管理、服务的常态化。

4.2 精准健康摸排, 就业稳心稳住稳当

把疫情时期的心理健康制度完善一遍, 把执行方案全面落实一遍, 把 班主任、导师和朋辈互助员线上培训一遍, 把心理健康危机排查内容细化 一遍, 力争把 “四个一” 做到全体学生全覆盖, 达到 “科学排查、逐个篮查、 特殊登记、一事一报”, 及时发现疫情暴露出来的共性问题, 抓好毕业生重 点群体和承受多重应激压力源学生的关注, 做到 “听之以耳, 听之以心”。 同时, 就业辅导员给予该生就业帮扶, 学院针对毕业生群体, 实施分类帮扶 和 “一生一策” 动态数据管理, 建立实时精准的工作台账, 并邀请企业HR、 优秀校友线上分享就疫情下的招聘需求形势、制定求职策略、线上应聘技 巧等, 鼓励先就业再择业, 稳住学生良好的就业心态, 保持就业率持续向好 的状态。

4. 3协同多方合力, 全程育德育心育才

“疫” 不容缓, 辅导老师、导师、女友与家长实时联系沟通, 搭建多 方沟通平台, 联动集中发力、持续给力、共同助力, 让学生自己发现 “近 距离” 支持力量。教育通过学校、家庭、社会协同发力, 以心促德, 以德 润人, 育德育心相互促进, 形成学校、家庭和社会三位一体的全面育人工 作格局。同时, 多方合力要有爱心和耐心, 了解学生所思所想所虑, 知晓学 生所需所求所盼, 解答所难所困所惑, 缓解理想与现实之间的冲突, 贴心为 学生营造和谐健康氛围, 巩固良性互助的情感纽带, 完善心理支持体系, 强 化价值引领, 促进学生与周边人良性互动, 增进沟通理解, 切实提高学生的 安全感、获得感、幸福感。

\section{[参考文献]}

[1] 生富,蔡士栋.大学生空心病的成因及干预[J].教书育人(高教论 坛),2018(06):52-53.

[2]张秀梅. 大学生心理健康现状及对比研究——以福州大学为研究 个案[J].社会心理科学,2007(Z3):209-213.

[3]谭亚菲.谈心理咨询技术在大学生心理健康教育教学中的运用 [J]. 亚太教育,2015(22):246-247.

\section{作者简介：}

江洁(1988--),女,汉族,湖南新化人,中级职称,硕士,研究方向：大 学生心理健康。 